\title{
Postprandial effects of beetroot enriched bread on peripheral microvascular function and blood pressure in normotensive men
}

\author{
D. A. Hobbs ${ }^{1,2}$, T. W. George $\mathrm{e}^{1,2}$, L. Methven ${ }^{1}$ and J. A. Lovegrove $\mathrm{C}^{1,2}$ \\ ${ }^{1}$ Department of Food and Nutritional Sciences and ${ }^{2}$ Institute for Cardiovascular and Metabolic Research (ICMR), \\ University of Reading, Whiteknights, PO Box 226, Reading, Berks, RG6 6AP, UK
}

The cardio-protective effects of beetroot, such as blood pressure reduction ${ }^{(1)}$ have been attributed to its high nitrate content ${ }^{(2)}$. Following ingestion, dietary nitrate is reduced to nitrite by oral bacteria, and further to the vasodilator nitric oxide (NO) endogenously ${ }^{(3)}$. This study investigated the effects of enriching bread with nitrate-rich beetroot on postprandial peripheral microvascular function and blood pressure (BP).

Twenty four healthy men were recruited to a randomly controlled, single blind, cross-over, postprandial test meal study. Peripheral microvascular function was measured using laser Doppler imaging (LDI) with iontophoresis at baseline, 2, 4 and 6 hours after consumption of $200 \mathrm{~g}$ control bread (no beetroot, $<0.8 \mathrm{mM}$ nitrate) or $200 \mathrm{~g}$ bread enriched with $100 \mathrm{~g}$ red beetroot $6.4 \mathrm{mM}$ nitrate). Ambulatory BP (ABP) was measured at baseline, every 30 min from 8 am until $10 \mathrm{pm}$, and every 60 min from 10 pm until 8 am, and blood samples were taken at baseline and 30,60, 90,120,150, 180, 210, 240, 300, 360 and 420 min after consumption of intervention breads. The participants followed a low nitrate and nitrite diet for 48 hours prior to and during the study day. A low nitrate and nitrite standard meal was provided for the evening before the study day.

Preliminary results show a significant reduction in diastolic BP (DBP) from 0 to 120 minutes post ingestion of beetroot enriched bread compared to the control bread (no beetroot) (Fig. 1A, $P=0.025)$. Endothelium-dependent (LDI-ACh, Fig. 1B) and endotheliumindependent (LDI-SNP) vasodilation increased following ingestion of beetroot enriched bread, compared to the control bread (no beetroot), but did not reach statistical significance (LDI-ACh, $P=0.08$ ). Plasma nitrite concentration significantly increased from 0 to 7 hours after ingestion of beetroot enriched bread compared to control (no beetroot) (Fig. 1C, $P=0.01$ ).
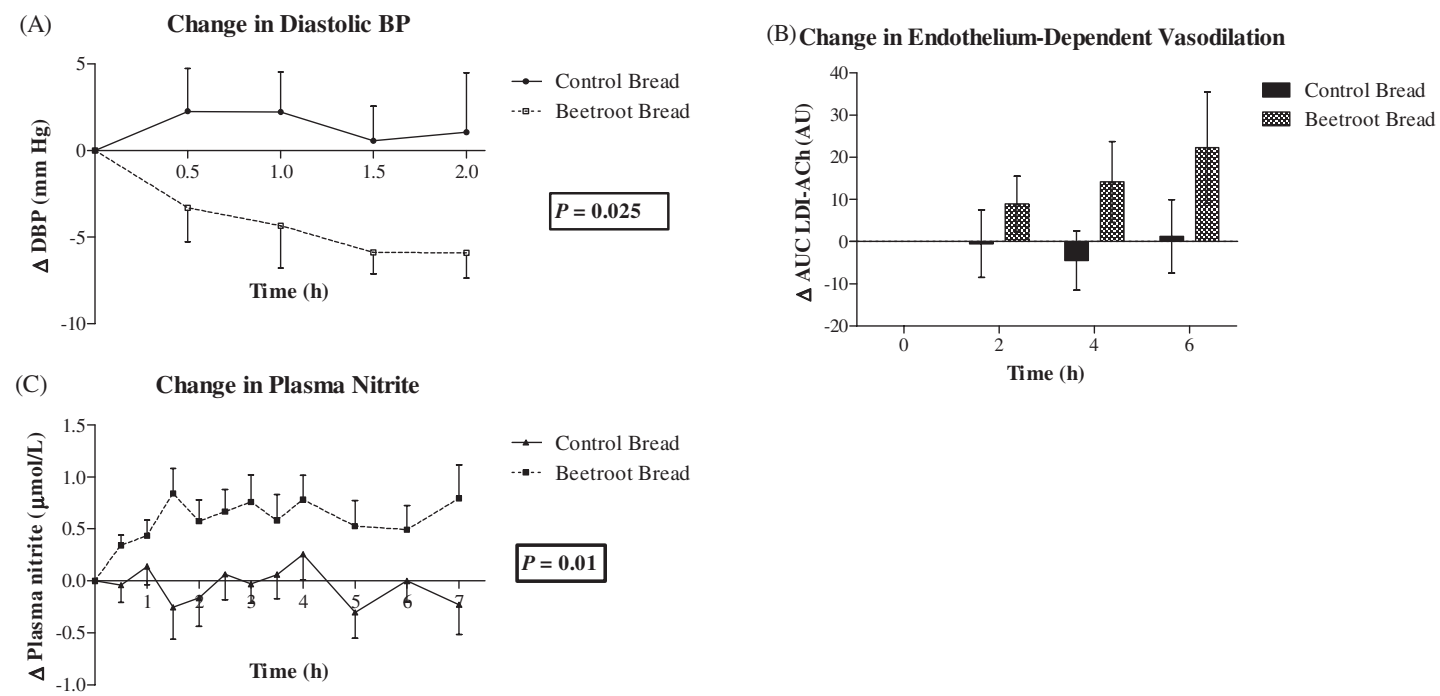

Fig. 1. The effect of beetroot enriched bread on the change from baseline in (A) diastolic BP (B) LDI-ACh response and (C) plasma nitrite concentrations. Data expressed as means \pm SEM.

In conclusion, this study demonstrated significant blood pressure lowering and a tendency for increasing peripheral microvascular function after ingestion of beetroot enriched bread, occurring in conjunction with a significant increase in plasma nitrite concentration. Beetroot enriched bread may serve as a good vehicle to increase consumption of cardio-protective beetroot in the diet.

1. Webb AJ, Patel N, Loukogeorgakis S et al. (2008) Hypertension 51(3), 784-90.

2. Lundberg JO, Weitzberg E, Cole JA et al. (2004) Nat Rev Micro 2, 593-602.

3. Lundberg JO, Weitzberg E \& Gladwin MT (2008) Nat Rev Drug Discov 7(2), 156-67. 